\title{
The concept of complete dentistry
}

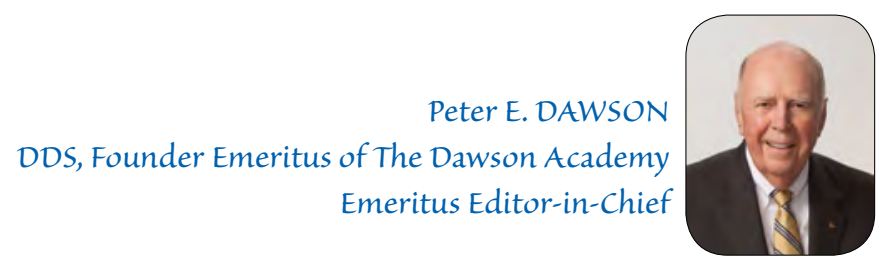

Dear readers,

There is an awakeninggoing on in dentistry today. The "tooth dentists" of yesterday are slowly but surely being transformed into physicians of the total masticatory system. And it is a transformation that is long past due.

Expanding the scope of dentistry in no way minimizes the importance of the teeth as a primary focus. It actually raises the bar for dentists to better understand why the interrelationship between the teeth and the rest of the masticatory system structures is so critical. A dentist who does not understand how important the relationship is between the teeth, the TMJs, and the total masticatory neuromusculature can be no better than a mediocre "tooth dentist". A practitioner who ignores the relationship of the airway to various types of dental malocclusions deprives patients of a potential life-changing treatment. If the relationship between occlusal disharmony and orofacial pain is ignored patients suffer needlessly. (And dentists fail to satisfy patients who are less than happy with their treatment results).

Teeth are made up primarily of neurogenic origin, and as such, they are sensors to the oral, facial and total masticatory system neuromusculature. Occluso-muscle disorders are the most common explanation for persistent problems seen in every dental office. Yet, they are routinely left undiagnosed or misdiagnosed by dentists who do not understand the exquisite interrelationship required for harmony within the gnathostomatic system.

Routine problems in every dental office such as sore teeth, fractured cusps, excessive wear problems and tooth hypermobility are all classified as occlusal diseases. Signs and symptoms that are the direct result of disharmony between the teeth and the position and condition of the TMJs are not just responsible for many toothaches. Occlusal disharmony triggers an array of pain symptoms that often include tension headaches and pain in the head, face or in the region of the jaw joints. Diagnosis and treatment of such disorders properly falls as a responsibility of complete dentists. There is no other medical specialist with the necessary training to accept this responsibility.

If the importance of functional harmony within the masticatory system is understood as a major factor for diagnosis and treatment in every dental office, one is left to wonder why functional occlusion has not been given a more important position in the training of dental school graduates. It is past time to correct this shortcoming in dental education.

Sincerely yours,

P.E. Dawson

Emeritus Editor-in-Chief

NOTE: "The Complete Dentist Manual" by Peter Dawson and John Cranham addresses the current shortcomings in dental practice and also outlines practical approaches for elevating the level of patient care. Instructions are simplified for easy understanding and the entire manual is profusely illustrated in color. It is available through Amazon Books. 